\title{
Interactive comment on "Impact of convectively lofted ice on the seasonal cycle of tropical lower stratospheric water vapor" by Xun Wang et al.
}

\section{Xun Wang et al.}

xunwang1009@tamu.edu

Received and published: 17 August 2019

1. "In some places, the manuscript seems to indicate that the purpose of the paper is to diagnose what is happening in the GEOSCCM model. However, in the abstract and several places in the main text, the authors seem to be arguing that the modeling framework here is useful for understanding what is happening in the real atmosphere. This distinction should be made clear such that readers are not given a misleading impression."

Our goal is to use the GEOSCCM to help us interpret the MLS data. The argument we are making is this:

1) We have identified features in the MLS data that cannot be reproduced by trajec- 
tory models just using temperature to regulate water vapor: The MLS shows that the seasonal oscillation of $100-\mathrm{hPa}$ water vapor in the northern hemispheric subtropics is larger than that in the southern hemispheric subtropics. A trajectory model driven by temperature and transport doesn't reproduce this. Adding more detailed microphysics (the Cloud Model) to the dehydration process of the trajectory model doesn't reproduce the observed hemispheric asymmetry either.

Interactive

comment

2) We show that a chemistry-climate model reproduces the MLS water vapor seasonal cycle.

3) In that model, we show that moistening by convective ice evaporation is responsible for the hemispheric asymmetry in the water vapor seasonal cycle.

4) We argue that this gives us insight into what's going on in the real world. Obviously, the amount of credence someone gives this argument is a judgment call. But it is our view that this argument is quite strong, particularly since there is no competing hypothesis for the asymmetry. And neither of the other reviewers had a problem with our approach.

In the revised version, we will edit the document to make sure the chain of logic in the paper is clear.

2. "The height distributions shown in Figure 3 show a reasonable agreement. However, as noted in passing by the authors, the CALIOP cloud products include convectivelygenerated clouds as well as clouds formed in situ in the upper troposphere..."

"Figure 4 shows geographic distributions of the CALIOP and GEOSCCM IWC integrated between 177 and $68 \mathrm{hPa}$. This layer average is dominated by ice at the lowest model level included $(177 \mathrm{hPa})$, and it is therefore not useful for assessing the realism of the GEOSCCM anvil IWC in the vicinity of the tropical tropopause. Comparisons of the CALIOP and GEOSCCM IWC at 100 and $82 \mathrm{hPa}$ would be more useful for this purpose.." 
This is a good point and one that requires us to make clear a few points. First, our goal is not to validate the GEOSCCM; we agree that our comparisons to CALIOP suggests it has too much convective ice in the TTL. Rather, as we described above, our goal is to show that differences between the MLS and temperature-only trajectory models also exist in a parallel analysis of the GEOSCCM; and that the differences in the GEOSCCM analysis can be largely fixed if we add convection into the trajectory model. As described below, we have performed sensitivity analyses that show that this conclusion is robust to the amount of convective ice in the GEOSCCM, so convective ice overestimates in the GEOSCCM do not impact our result.

To make these points clear, we will substantially edit our discussion of GEOSCCM convective ice. We show in Figure 1 an updated comparison between CALIOP and GEOSCCM ice data. For the CALIOP, we show the ice from all clouds minus the ice from thin cirrus clouds above $146 \mathrm{hPa}$ during 200805 - 201312 (private communication from Tao Wang), which is a rough estimate of convective ice in the TTL region, although it is almost certainly an underestimate of true convective ice amount. For the GEOSCCM, we show the total convective ice, as well as the convective ice decreased by $90 \%$ and $80 \%$. The vertical profile of $30 \mathrm{~N}-30$ S convective ice (Fig. 2) shows that a decrease of $80 \%$ brings tropical mean GEOSCCM convective ice into better agreement with CALIOP values at $121 \mathrm{hPa}$ and above.

Fig. 3 shows the distribution of convective ice averaged between $121-82 \mathrm{hPa}$ during JJA (top) and DJF (bottom). We then use the decreased convective ice data from the GEOSCCM to produce two trajectory test runs. Fig. 4 shows the $100-\mathrm{hPa}$ water vapor seasonal cycle produced by the GEOSCCM and by trajectory models with convective ice decreased by various amounts as well as one run with no ice. Reducing the GEOSCCM IWC to bring it into agreement with CALIOP IWC does not change the conclusion that adding ice helps improve the seasonal cycle in the trajectory simulation of the GEOSCCM.

3. "Further, the conclusions presented here contradict various other lines of evidence 
suggesting that direct ice injection by deep convection has a relatively small impact on stratospheric humidity; acknowledgment and discussion of these discrepancies is generally lacking in the manuscript."

"Various lines of evidence indicate that direct injection of ice into the lower stratosphere by deep convection has a relatively weak impact on stratospheric humidity. Numerous studies over the past 20 years have documented the strong correlation between tropical cold-point tropopause temperature and the lower stratospheric humidity (e.g. Randel et al., 2004; Fujiwara et al., 2010; Liang et al., 2011; Fueglistaler et al., 2013). This strong coupling would break down if direct convective injection significantly contributed to the stratospheric water vapor budget."

"Direct calculations conducted by a co-author on this paper indicate a far smaller impact of convective hydration on lower stratospheric humidity (Schoeberl et al., 2018)..."

Previous studies, including those that Jensen cites, show strong coupling between the fluctuations in water vapor and fluctuations in the TTL temperature on interannual time scales. We agree that these are tightly connected - in fact, Dessler et al. (2016) showed that the GEOSCCM also reproduces this tight coupling (see Fig. 4 of that paper and discussion). However, none of these papers quantify the impact of convection on the seasonal cycle and therefore do not contradict our analysis.

Schoeberl et al. (2018) quantifies convection and concludes it is not important, but his analysis only covered DJF of 2008/09. Thus, that paper does not tell us anything about the main conclusions of our paper - that summertime convection is important for $\mathrm{NH}$ seasonal cycle. Fueglistaler et al. (2013), pointed out that the trajectory model using the Lagrangian Dry Point (LDP) has a dry bias when predicting the annual mean entry water vapor. They then showed that employing a cloud microphysical box model for the dehydration better reproduces the observed annual mean entry water vapor in the tropics $\left(25^{\circ} \mathrm{N}-25^{\circ} \mathrm{S}\right)$, but tends to underestimate the seasonal amplitude of the MLS and HALOE water vapor. Their result is consistent with the conclusion of this paper

Printer-friendly version

Discussion paper
Interactive

comment 
that temperature variations alone are not sufficient to produce all the features of the LS water vapor seasonal cycle.

4. "Further, as shown by Dessler et al. (2007) and others, a significant contribution from sublimation of convectively-lofted ice to the lower stratospheric humidity would result in higher water isotope (HDO) enrichment than indicated by satellite and in situ observations."

We agree that more work should be done on HDO and we have now put in a statement to that effect. However, we do not think that this is a strong argument against our conclusions. One thing that is clear in the $20+$ years people have been analyzing stratospheric HDO is that it is not a strong constraint on water vapor processes and multiple sets of processes can produce the observed HDO fields. For example, Dessler et al. (2007) argues convection is required to explain stratospheric HDO, but Gettelman and Webster (2005) argue that it is not required. It is our hope that our paper will motivate future work on this issue.

5. "The authors conclude that most of the convective moistening in their simulations comes from the Asian monsoon region. However, analyses of convective moistening using aircraft and satellite (MLS) measurements suggest that this process primarily occurs over the north American monsoon region where the tropopause is relatively low and deep convection extends well into the lower stratosphere (Schwartz et al., 2013; Smith et al., 2017)."

Neither of the papers cited actually say what Jensen says they do. Schwartz et al. (2013) shows that extremely large water vapor values are observed by the MLS over both North America (NA) and the Asian monsoon anticyclone region (AMA). They make no claims about whether the NA monsoon is more or less important than the Asian monsoon. The study by Smith et al. (2017) shows that deep convection is observed to contribute to high frequency of enhanced water vapor over the central U.S. during boreal summer. Their paper doesn't reach any conclusions about the Asian monsoon 
region. Thus, neither of these papers contradict anything in our paper.

It is possible that the GEOSCCM trajectory model underestimates the convective impact over the NA region, since at 100 and $82 \mathrm{hPa}$, the GEOSCCM underestimates the convective ice amount in the NA region. This is mentioned in the submitted paper (line 281-284). In the revised paper, we'll make this point clearer.

6. "The FDF model parcels are launched at $370 \mathrm{~K}$ potential temperature. Particularly during Boreal summertime, the tropical cold point tropopause is often below $370 \mathrm{~K}$; therefore, some of the parcels are not experiencing the true Lagrangian dry point..."

This is a good point and we have addressed it by re-running the model simulations with parcels initialized at $360 \mathrm{~K}$. The analysis and plots in the paper will be updated with these new runs. While some details of the plots have changed, the trajectory model is still unable to simulate the seasonal cycle in the $\mathrm{NH}$ subtropics when water vapor is regulated only by temperature (Fig. 5).

We also did three test runs using ERAi, MERRA2, and GEOSCCM meteorology where we initialize the parcels above the local level of zero heating rate (Fig. 6 below). These runs agree closely with those initialized at $360 \mathrm{~K}$ and they also show that temperature alone can't reproduce the larger LS water vapor seasonal cycle in the $\mathrm{NH}$ subtropics as shown in the MLS and GEOSCCM.

We will replace all analyses in the revised version of the paper with runs initialized at $360 \mathrm{~K}$.

7. "The manuscript states that ice forms at $80 \%$ relative humidity with respect to ice..."

It is correct that we limit water vapor in the parcels to $80 \%$ relative humidity. We could've used $100 \%$ relative humidity and the conclusion about the hemispheric asymmetry would remain the same, except the water vapor values would be higher everywhere by a factor of 1.1-1.2 at $100 \mathrm{hPa}$ and $82 \mathrm{hPa}$. The choice of saturation threshold does not disproportionately affect ice evaporation. As discussed in Dessler et al., (2016) in

Interactive

comment
Printer-friendly version

Discussion paper 
some detail, our choice of $80 \%$ is motivated by the fact that the trajectory model fields agree better with the GEOSCCM than when using $100 \%$.

The key point here is that, whether using $100 \%$ or $80 \%$ threshold, convective moistening still needs to be included in order to reproduce the seasonal cycle in the $\mathrm{NH}$ subtropics and the hemispheric asymmetry. To demonstrate this, we show the zonal mean water vapor seasonal cycles from the GEOSCCM trajectory model using the $100 \% \mathrm{RH}$ saturation threshold together with that using the $80 \% \mathrm{RH}$ saturation threshold (Fig. 7). Indeed, the water vapor values in the $100 \%-\mathrm{RH}$ run are about 1.1 to 1.2 larger everywhere at $100 \mathrm{hPa}$ and $82 \mathrm{hPa}$ compared to the $80 \%-\mathrm{RH}$ run. However, this does not reproduce the observed seasonal cycle in the $\mathrm{NH}$ subtropics or the hemispheric asymmetry. Thus, our results are robust to the choice of threshold.

\section{References}

Dessler, A. E., Hanisco, T. F. and Fueglistaler, S.: Effects of convective ice lofting on $\mathrm{H}$ $2 \mathrm{O}$ and HDO in the tropical tropopause layer, J. Geophys. Res., 112(D18), D18309, doi:10.1029/2007JD008609, 2007.

Dessler, A. E., Ye, H., Wang, T., Schoeberl, M. R., Oman, L. D., Douglass, A. R., Butler, A. H., Rosenlof, K. H., Davis, S. M. and Portmann, R. W.: Transport of ice into the stratosphere and the humidification of the stratosphere over the 21st century, Geophys. Res. Lett., 43(5), 2323-2329, doi:10.1002/2016GL067991, 2016.

Fueglistaler, S., Liu, Y. S., Flannaghan, T. J., Haynes, P. H., Dee, D. P., Read, W. J., Remsberg, E. E., Thomason, L. W., Hurst, D. F., Lanzante, J. R. and Bernath, P. F.: The relation between atmospheric humidity and temperature trends for stratospheric water, J. Geophys. Res. Atmos., 118(2), 1052-1074, doi:10.1002/jgrd.50157, 2013.

Gettelman, Andrew; Webster, C. R.: Simulations of water isotope abundances in the upper troposphere and lower stratosphere and implications for stratosphere troposphere exchange, J. Geophys. Res., 110(D17), D17301, doi:10.1029/2004JD004812, 


\section{5.}

Schoeberl, M. R., Jensen, E. J., Pfister, L., Ueyama, R., Avery, M. and Dessler, A. E.: ACPD Convective Hydration of the Upper Troposphere and Lower Stratosphere, J. Geophys. Res. Atmos., 123(9), 4583-4593, doi:10.1029/2018JD028286, 2018.

Schwartz, M. J., Read, W. G., Santee, M. L., Livesey, N. J., Froidevaux, L., Lambert, A. and Manney, G. L.: Convectively injected water vapor in the North American summer lowermost stratosphere, Geophys. Res. Lett., 40(10), 2316-2321, doi:10.1002/grl.50421, 2013.

Smith, J. B., Wilmouth, D. M., Bedka, K. M., Bowman, K. P., Homeyer, C. R., Dykema, J. A., Sargent, M. R., Clapp, C. E., Leroy, S. S., Sayres, D. S., Dean-Day, J. M., Paul Bui, T. and Anderson, J. G.: A case study of convectively sourced water vapor observed in the overworld stratosphere over the United States, J. Geophys. Res. Atmos., 122(17), 9529-9554, doi:10.1002/2017JD026831, 2017.

Interactive comment on Atmos. Chem. Phys. Discuss., https://doi.org/10.5194/acp-2019-302, 2019. 

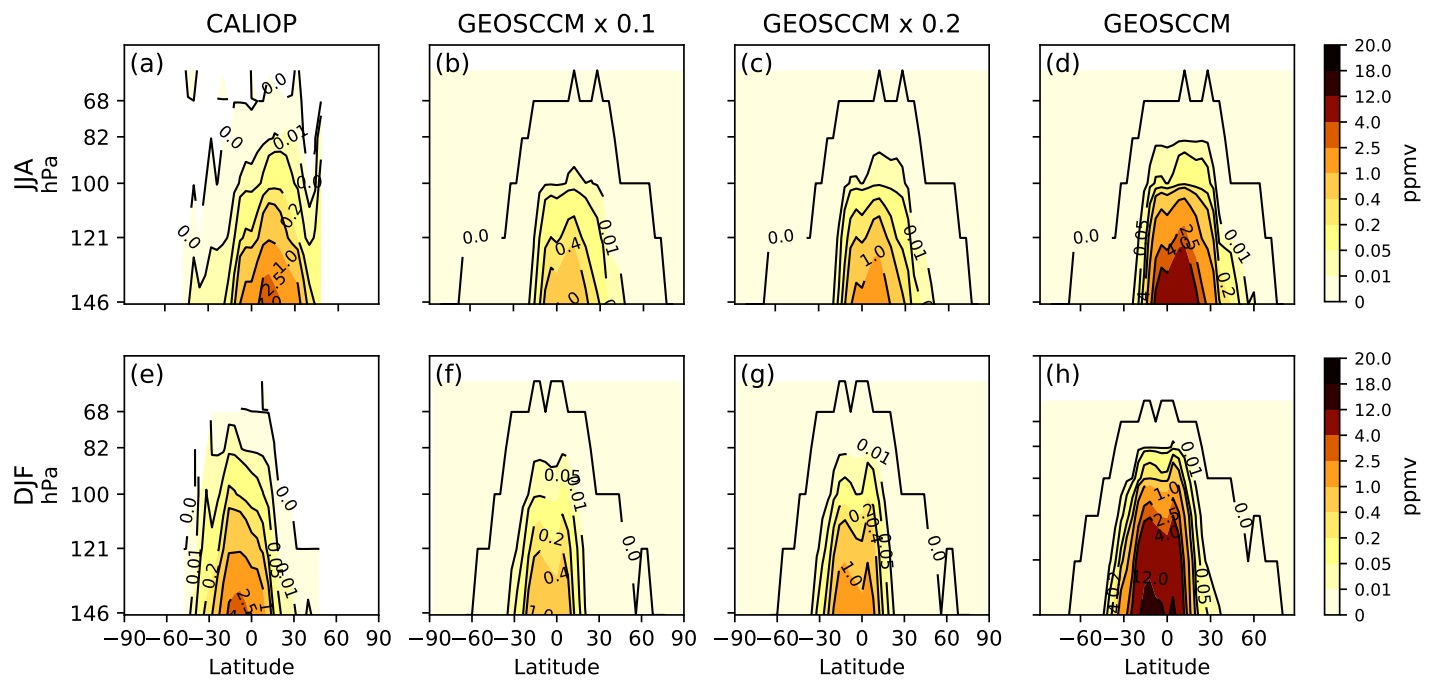

Fig. 1. CALIOP, GEOSCCM, and reduced GEOSCCM zonal mean convective ice in a pressurelatitude domain.

\section{Interactive}

comment 

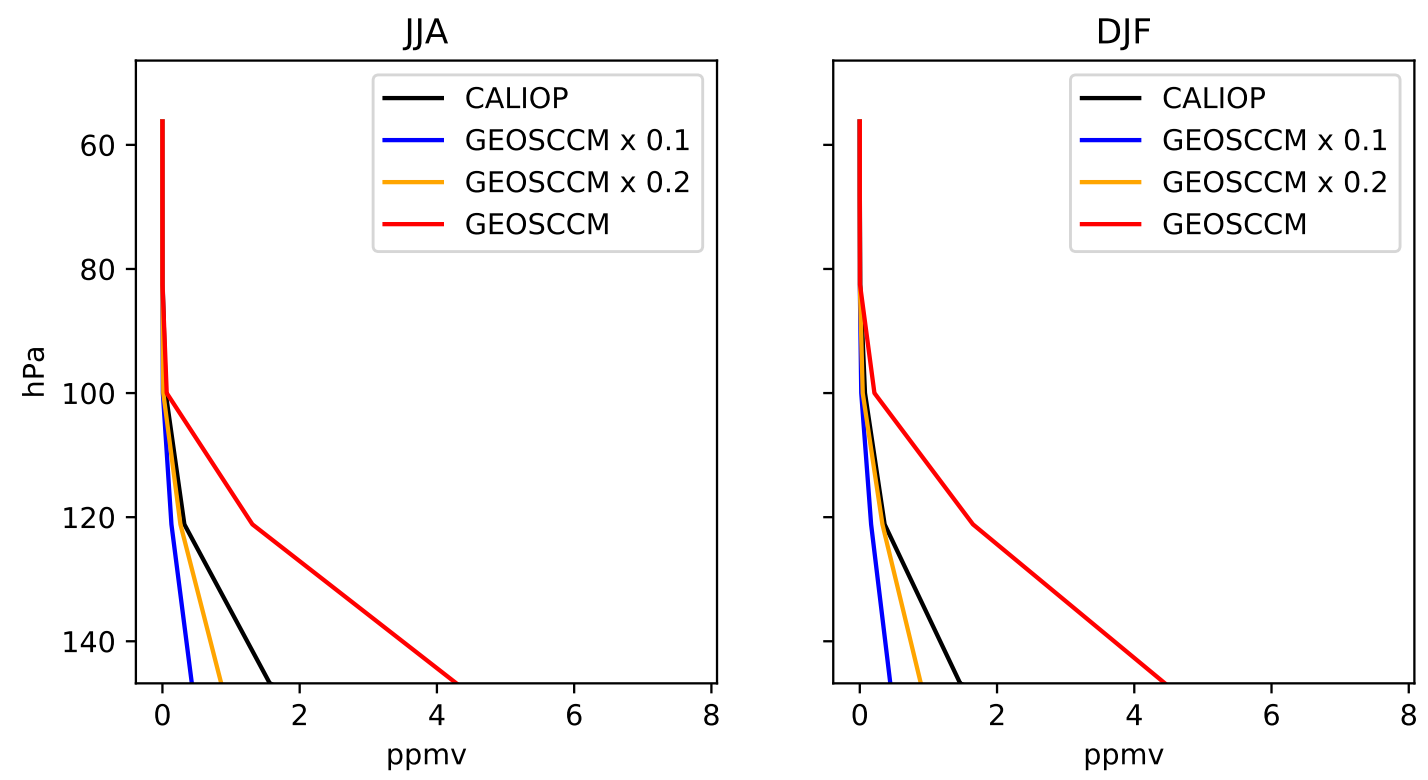

Interactive

comment

Fig. 2. CALIOP, GEOSCCM, and reduced GEOSCCM convective ice (ppmv) profile averaged between $30^{\circ} \mathrm{N}-30^{\circ} \mathrm{S}$. 
Interactive

comment
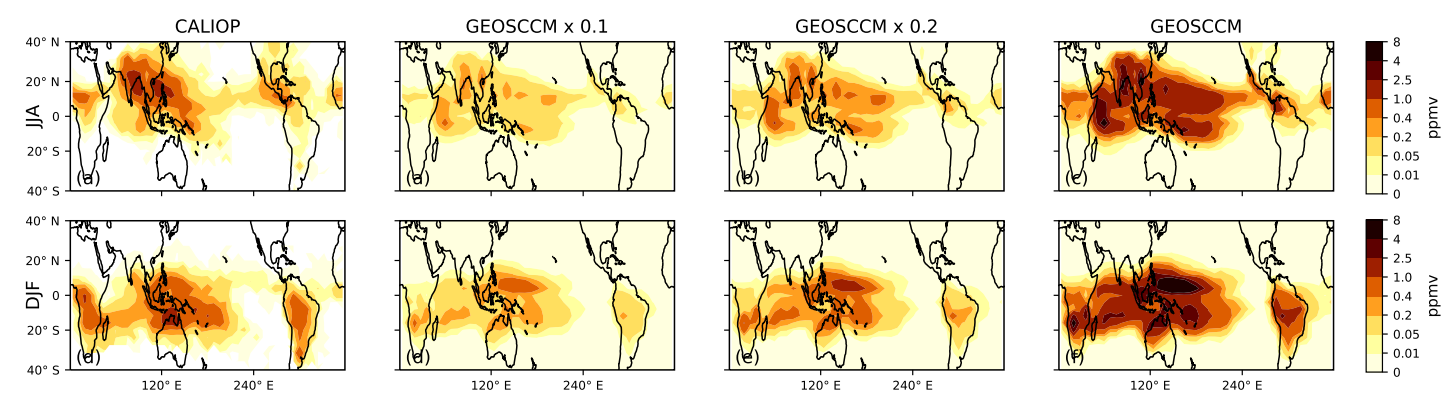

Fig. 3. Same as Fig. 1, but for CALIOP and GEOSCCM ice averaged between $121-82 \mathrm{hPa}$ in a latitude- longitude domain. 
Interactive

comment

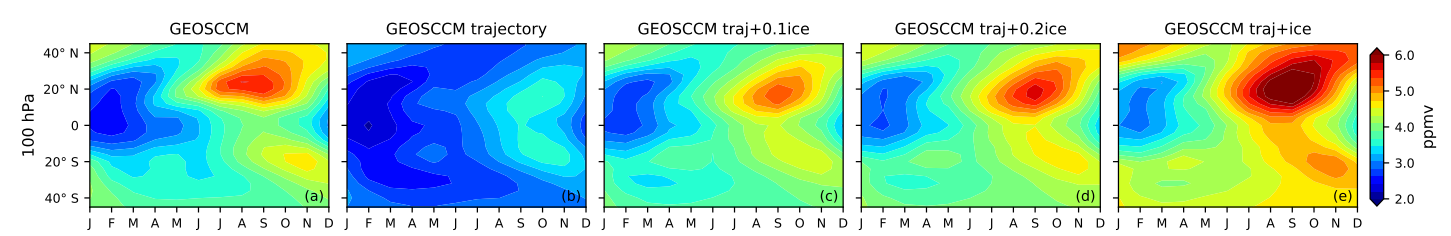

Fig. 4. Zonal mean water vapor seasonal cycle at $100 \mathrm{hPa}$ from GEOSCCM, GEOSCCM trajectory, and GEOSCCM trajectory with with convective ice moistening. The trajectory models are initialized at $360 \mathrm{~K}$. 
Interactive

comment

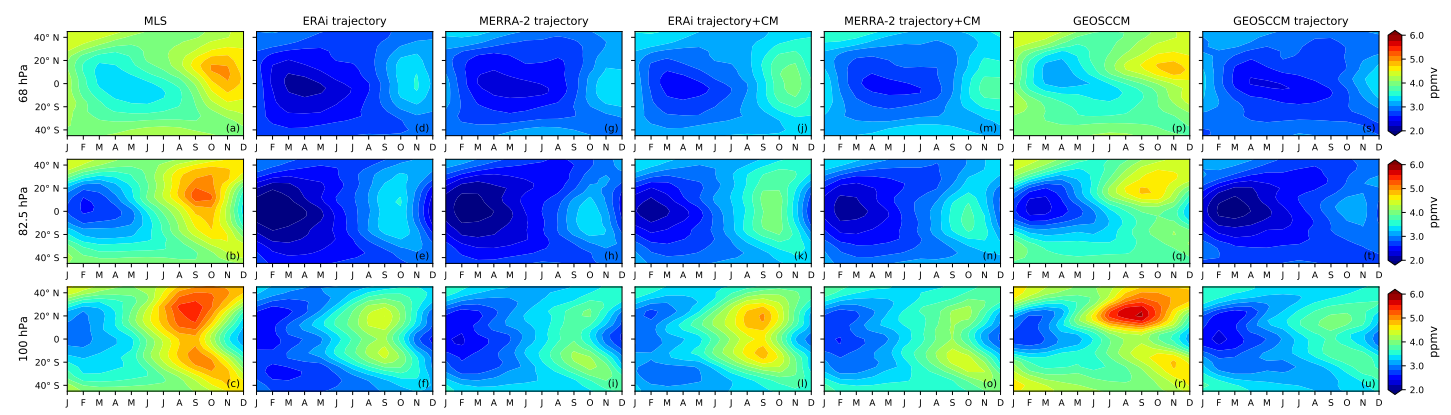

Fig. 5. Zonal mean water vapor seasonal cycle at 100, 82 , and $68 \mathrm{hPa}$ from MLS and trajectory models. The trajectory models are initialized at $360 \mathrm{~K}$. We used the averaging kernels for all modeled water vapor. 


\section{ACPD}
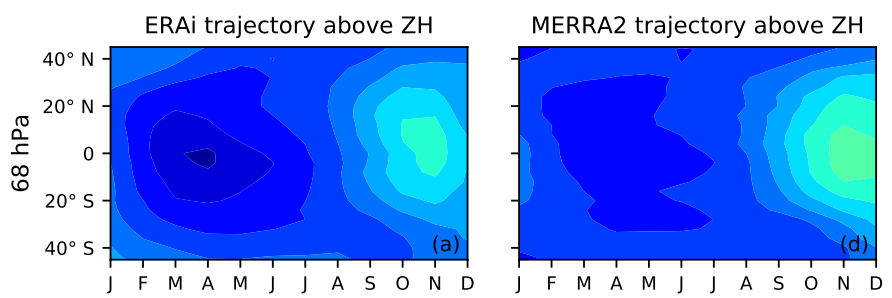

GEOSCCM trajectory above $\mathrm{ZH}$

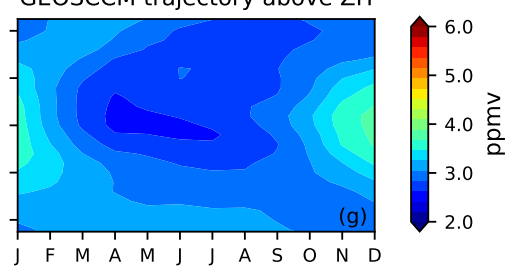

Interactive

comment
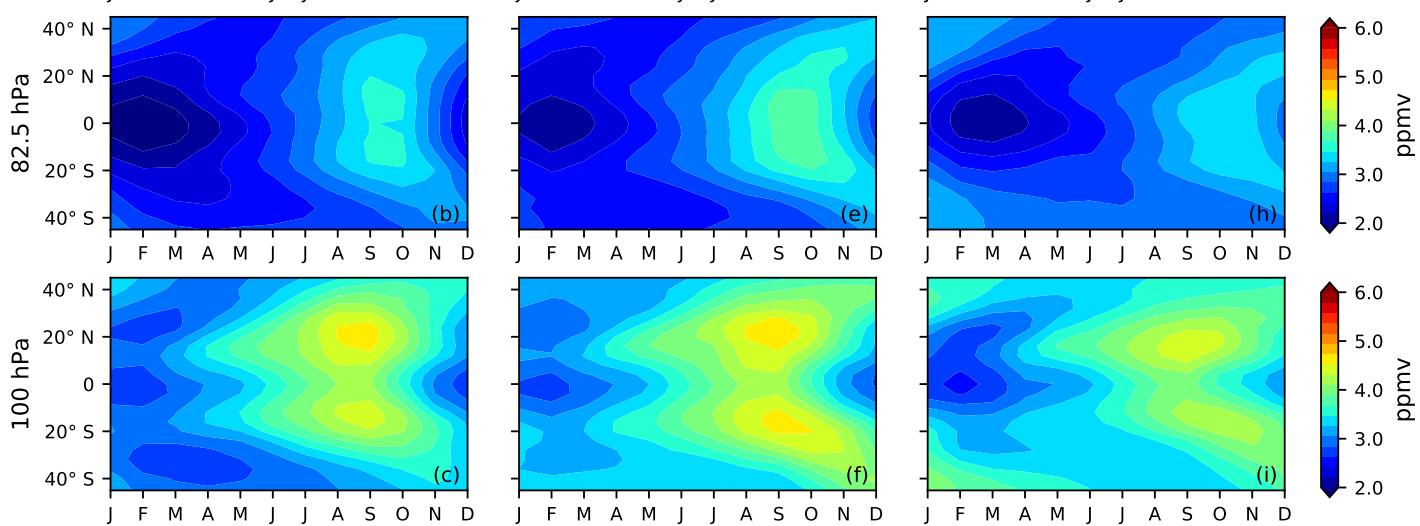

Fig. 6. Zonal mean water vapor seasonal cycle at 100,82 , and $68 \mathrm{hPa}$ from MLS and trajectory models. The trajectory models are initialized at local levels above zero heating rate. 


\section{ACPD}
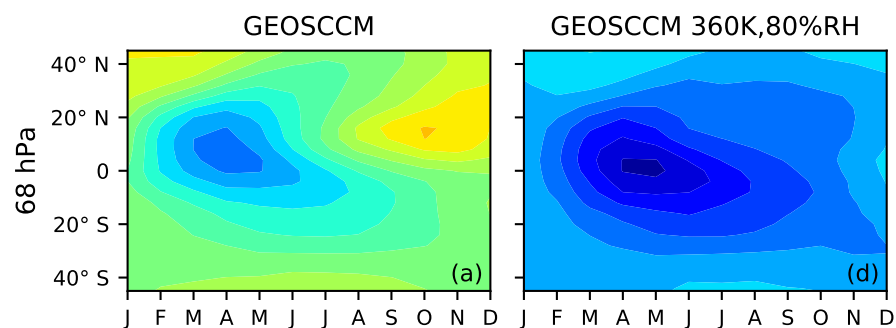

GEOSCCM $360 \mathrm{~K}, 100 \%$ RH

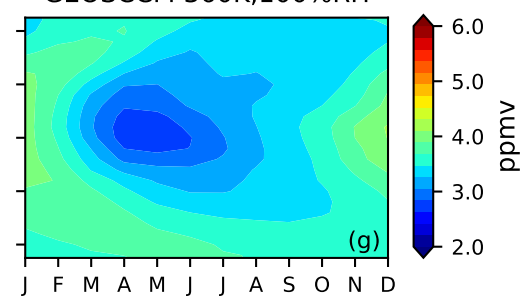

\section{Interactive}

comment
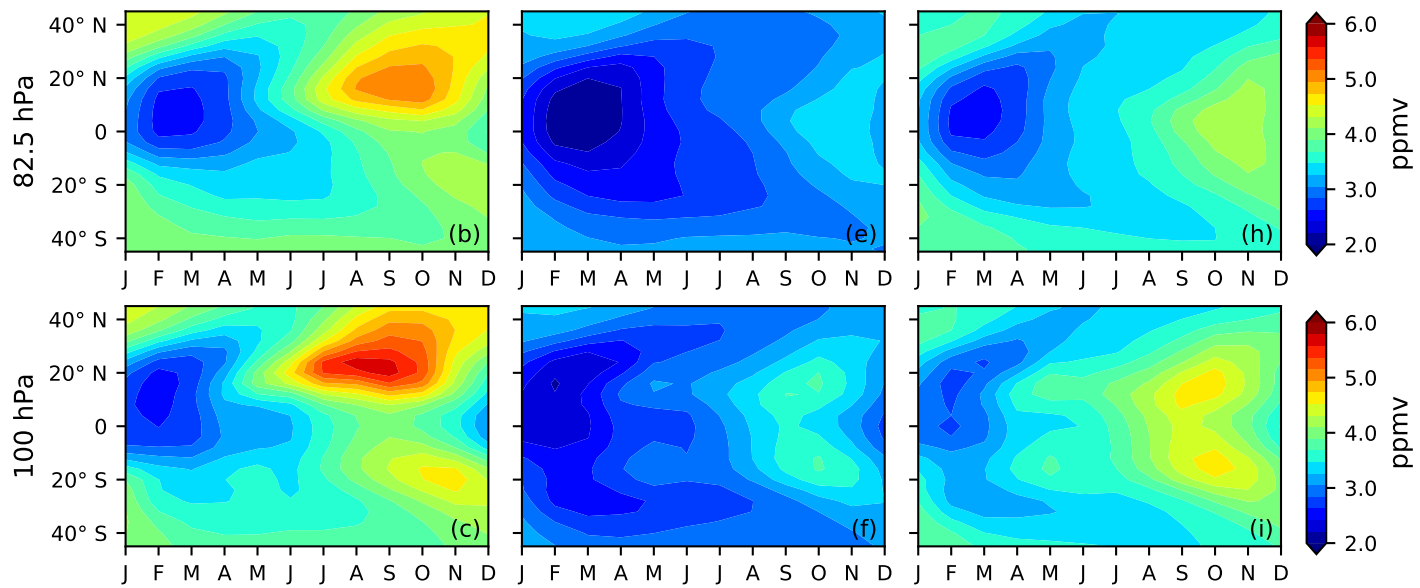

Fig. 7. Zonal mean water vapor seasonal cycles at 100, 82 , and $68 \mathrm{hPa}$ from GEOSCCM and trajectory models. We show trajectory models initialized at $360 \mathrm{~K}$, using two saturation thresholds: $80 \% \mathrm{RH}$ and $100 \% \mathrm{RH}$. 